\title{
Efficacy of climatic change on the development of two strains of stalk borer, Ostrinia nubilalis (Lepidoptera: Crambidae), treated with challenger/silica nanoparticles
}

\author{
Amany Ramadan Ebeid(D)
}

\begin{abstract}
Background: The European corn borer, Ostrinia nubilalis (Hüb.) (Lepidoptera: Crambidae), is an important pest that disturbs the economic yield of Egyptian crops especially the corn plant.

Results: We examined the rate of development of two strains (one from Sharqia Governorate and the other from Qena Governorate) treated with challenger/silica nanoparticle formulation within a range of temperatures $\left(15\right.$ to $\left.45^{\circ} \mathrm{C}\right)$. The developmental period and thermal requirements (DD) of $O$. nubilalis at four constant temperatures $(15,25,35$, and $45^{\circ} \mathrm{C}$ ) were significantly different between each other. The developmental rate of both strains increased significantly with the increase of temperature. The estimated life table for both treated populations from different two localities predicted their population dynamics.

Conclusion: The duration and thermal requirements of two populations of the silica nanoparticle-treated strains of Ostrinia nubilalis (Hüb.) from different localities, and its development at four tested constant temperatures were significantly different between each other. Such information and life table are crucial to predict the seasonal abundance of the adult $O$. nubilalis in the field, which is essential for the successful implantation of control measures and enables us to determine the best time for controlling with better performance.
\end{abstract}

Keywords: Constant temperature, European corn borer, Ostrinia nubilalis, Silica nanoparticles, Thermal requirements

\section{Background}

European corn borer has a widespread host range, attacking practically all herbaceous plants. Their generation number depends on climatic factors, and there is a considerable adaptation for climate conditions even within strains. Ostrinia nubilalis is one of the serious pests among corn borers that infest grain corn causing severe reductions in corn production. Their development, survival rate, geographical distribution, and population density are strongly influenced by either insecticides or the prevailing temperature in the field (Ebeid, 2012; Ebeid et al., 2017).

Nanotechnology is a new environmental field that could be effective in reducing the cost of some pesticides

Correspondence: amanyr2@hotmail.com

Pests and Plant Protection Department, National Research Centre, Dokki, Cairo, Egypt and might be helpful in keeping the environment from pollution (Chinnamuthu and Boopathi, 2009).

The biological development depends on the received amount of heat units "Degree thermal-Days" (DD) to complete one generation as well as the lower threshold temperature for each insect, where no development occurs below that level (Roy et al., 2003). These values may be used in predicting insect activity during the growing season (Ebeid et al., 2015).

The conducted life table studies on corn borer populations perhaps provide the description for the population developmental rate under different temperatures, as well as prediction for population technique of the pest. Also, to develop the mass-rearing dynamics of the most important biological control agents to be used in Integrated Pest Management (IPM) program (Sedighi et al., 2016). Among the life table parameters are the rate of intrinsic 
$\left(r_{m}\right)$, the rate of net reproduction $\left(R_{0}\right)$, and the mean generation time (Chi and $\mathrm{Su}, 2006$ ).

The goal of this paper is to compare between the two different strains of $O$. nubilalis according to their localities and their effect by challenger/silica nanoparticle formulation treatment, with respect to their developmental progress and change in temperature, life table, and to determinate the zero of developmental values for the different stages of $O$. nubilalis strains to detect the change that occurred during the emergence of adult.

\section{Materials and methods Tested conditions}

Four constant temperatures $\left(15,25,35\right.$, and $\left.45^{\circ} \mathrm{C}\right)$ at $70 \pm 2 \% \mathrm{RH}$ are used to determine the thermal requirement as lower temperature threshold $\left(T_{0}\right)$, heat unit (DD), and life table for European corn borer, $O$. nubilalis.

\section{Tested material}

Silica nanoparticles/challenger formulation that applied was manufactured by the Refractories, Ceramics and Building Materials Department, National Research Centre, Giza, Egypt. Silica nanoparticles were served as a carrier for challenger $36 \% \mathrm{SC}$, a commercial formulation of chlorfenapyr pesticide, manufactured by BASF-The Chemical Company, New Jersey, USA. The recommended concentration (0.5\%) with two drops of Tween-80, as dispersant, was added and applied to larval diet (corn stalk) for 3 days and then feed on untreated food till pupation. Treatment was carried out by using dipping technique for $2 \mathrm{~min}$ and then left to dry (Ebeid et al., 2013). Treated larval stages were examined daily under the effect of different constant temperature till adult emergence.

\section{Experimental insects}

Two strains of European corn borer, Ostrinia nubilalis larvae, were collected from two Governorates (Sharqia and Qena Governorates), which represent different climatic conditions, were transferred into glass jars lined with moist saw dust to laboratory, and reared on corn tassel emerged from the whorl then stalk and ear at constant conditions $\left(35 \pm 2{ }^{\circ} \mathrm{C}\right.$ and $\left.75 \pm 5 \% \mathrm{RH}\right)$ till adult emergence and oviposition.

Egg masses were collected in Petri dishes $(10-\mathrm{cm}$ diameter) that lined with moist filter paper. Three replicates of egg (each has 30 individual) were conducted for each temperature. The developmental progress of each larval instar feeding on stalk treated with challenger/silica nanoparticles $(0.5 \%$ concentration) of the two tested strains was monitored until adult emergence at abovementioned constant temperatures.
A linear regression diagram was used to determinate the relationship between development rate and tested temperatures within the linear range, where the rate of development is calculated as the percent of inverse of the number of days required for development at that temperature. The resulting regression equation $(Y=a+b x)$ where $x$ is the temperature and $Y$ is the developmental rate used to estimate the lower temperature threshold "zero of development" ( $x$-intercept method $T_{0}=-a / b$ ) (Campbell et al., 1974).

Thermal unit (DD) accumulations for each tested temperature of the tested insects were calculated according to Campbell et al. (1974).

To construct the life table, the initial number of treated female, the fraction of egg reached maturity, and the actual female age were calculated. Moreover, the life table used to compare the impact of different temperatures on the population growth of $O$. nubilalis from the two localities is according to Chi and $\mathrm{Su}$ (2006) and Tuan et al. (2014).

\section{Statistical analysis}

Student $t$ test (independent samples $t$ test) was carried out through the SPSS computer program to discriminate differences between the two strains. The raw data were analyzed according to "TWOSEX-MSChart" computer program (Chi and $\mathrm{Su}, 2006)$.

\section{Results}

Developmental progress of Ostrinia nubilalis treated with silica nanoparticles at different constant temperature

Silica nanoparticles form affected the development of two treated strains of $O$. nubilalis at four constant temperatures, which revealed increase in developmental rate from egg to adult with increases in temperature (Fig. 1).

\section{Duration of different immature-treated stage}

At the prevailing temperature, the duration of all developmental stages (except prepupal stage at $15^{\circ} \mathrm{C}$ and pupal stage at $45^{\circ} \mathrm{C}$ ) of the Sharqia strain was significantly higher than that of the Qena strain (Tables 1 and 2).

\section{Developmental progress and thermal conditions of different strains \\ Egg stage}

With respect to the Sharqia strain, incubation period is significantly higher than that of the Qena strain, causing lower rate of development and consequently higher threshold temperature. The linear regressions revealed lower development threshold $\left(T_{O}\right)$ were 12.33 and 9.8 ${ }^{\circ} \mathrm{C}$ for the Sharqia and Qena strains, respectively. The decreasing of incubation period with increasing temperature leads to high rate of the development from 15 to $45^{\circ} \mathrm{C}$. Estimation of average thermal 


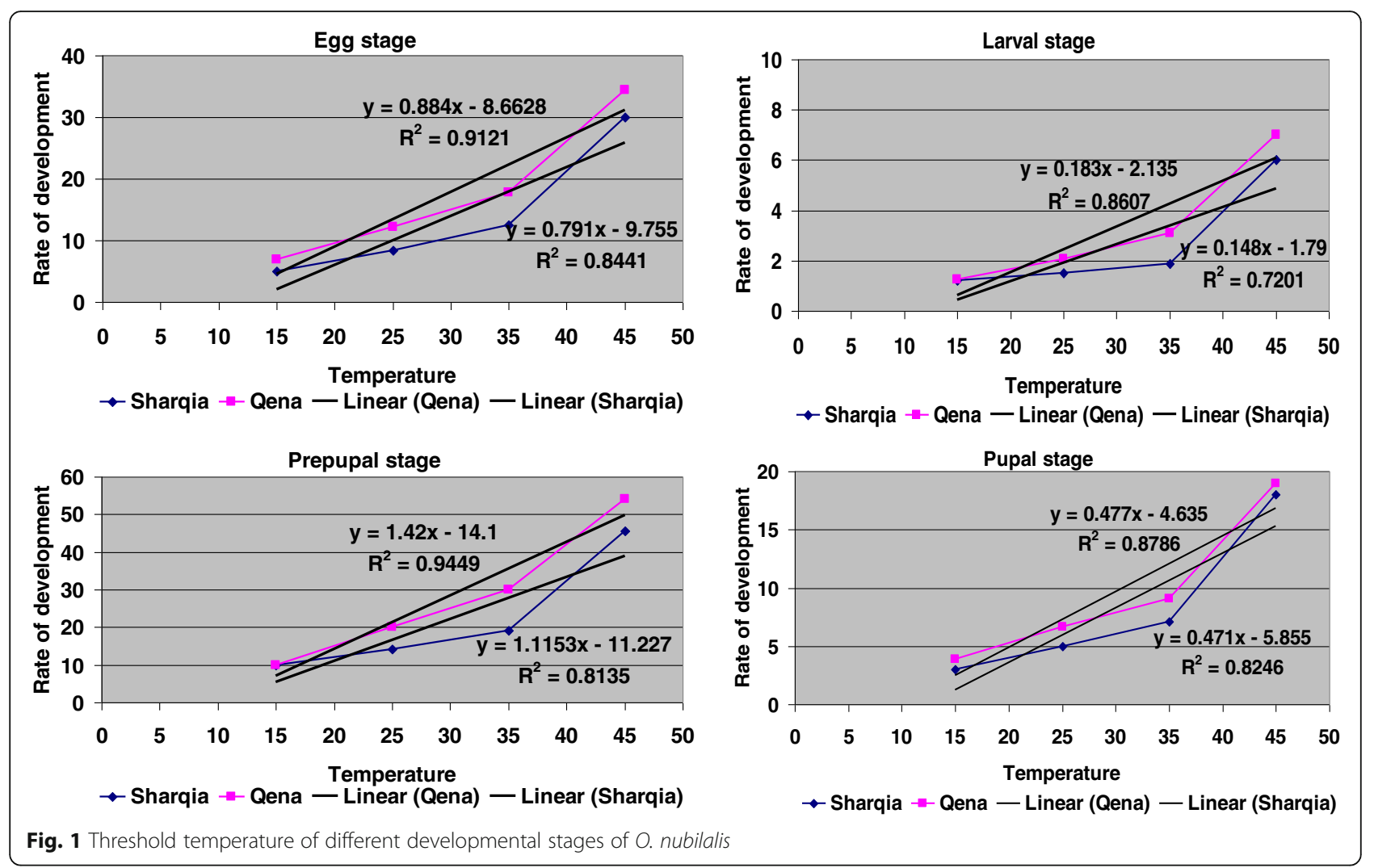

constants for egg stage was 123.34 DD and 110.68 DD for the Sharqia and Qena strains, respectively (Table 1 and Fig. 1).

\section{Larval stage}

The same trend was observed in case of treated larval stage, where the lower threshold temperatures $\left(T_{0}\right)$, and thermal constants for larval stages of $O$. nubilalis of the Sharqia strain were $\left(12.09^{\circ} \mathrm{C}\right.$ and $\left.714.47 \mathrm{DD}\right)$ as compared with that of the Qena strain $\left(11.67^{\circ} \mathrm{C}\right.$ and 534.63 DD) (Table 1 and Fig. 1).

\section{Prepupal stage}

The insignificant differences between the prepupal stage of O. nubilalis of two localities at $15^{\circ} \mathrm{C}$ lead to threshold temperatures $\left(T_{0}\right)$ for tested prepupal stages of the Sharqia strain $\left(10.06{ }^{\circ} \mathrm{C}\right)$ become nearly the same value to that of the Qena strain $\left(9.90^{\circ} \mathrm{C}\right)$ (Fig. 1). They were recording thermal units of 90.28 and $69.01 \mathrm{DD}$ for the Sharqia and Qena strains, respectively (Table 1).

\section{Pupal stage}

The treated pupal stage duration behaved the same trend, i.e., decreased with the increasing temperature. This decrease leading to the increase of the rate of development that affects the average thermal unit of the Sharqia strain to reach 209.5 DD, while the Qena strain recording 206.71 DD (Table 1). The lower threshold temperatures $\left(T_{0}\right)$ for pupal stages of Sesamia cretica

Table 1 Thermal requirements for treated O. nubilalis two strains from two different localities

\begin{tabular}{|c|c|c|c|c|c|c|c|c|c|}
\hline \multirow[t]{3}{*}{ Temperature } & & \multicolumn{2}{|c|}{ Egg stage } & \multicolumn{2}{|c|}{ Larval stage } & \multicolumn{2}{|c|}{ Prepupal stage } & \multicolumn{2}{|c|}{ Pupal stage } \\
\hline & & Sharqia & Qena & Sharqia & Qena & Sharqia & Qena & Sharqia & Qena \\
\hline & Zero of development $\left(T_{0}\right)$ & 12.33 & 9.80 & 12.09 & 11.67 & 10.06 & 9.90 & 12.40 & 9.72 \\
\hline $15^{\circ} \mathrm{C}$ & & 53.4 & 74.88 & 242.49 & 266.40 & 49.40 & 51.00 & 86.58 & 135.17 \\
\hline $25^{\circ} \mathrm{C}$ & $\mathrm{DD}$ & 150.77 & 124.64 & 860.71 & 647.84 & 105.18 & 75.50 & 252.00 & 228.13 \\
\hline $35^{\circ} \mathrm{C}$ & & 181.36 & 141.12 & 1205.10 & 750.99 & 129.69 & 82.83 & 318.21 & 277.83 \\
\hline $45^{\circ} \mathrm{C}$ & & 107.81 & 102.08 & 549.60 & 473.29 & 76.87 & 66.69 & 181.26 & 185.68 \\
\hline Average DD & & 123.34 & 110.68 & 714.47 & 534.63 & 90.284 & 69.01 & 209.5 & 206.71 \\
\hline
\end{tabular}


Table 2 Duration of different treated stages of $O$. nubilalis under different constant temperatures

\begin{tabular}{llllll}
\hline Temperature & Strain locality & Eggs stage & Larval stage & Prepupal stage & Pupal stage \\
\hline $15^{\circ} \mathrm{C}$ & Sharqia & $20.00 \pm 0.50 \mathrm{a}$ & $83.33 \pm 0.45 \mathrm{a}$ & $10.00 \pm 0.70 \mathrm{a}$ & $33.30 \pm 0.90 \mathrm{a}$ \\
& Qena & $14.40 \pm 0.75 \mathrm{~b}$ & $80.00 \pm 1.29 \mathrm{~b}$ & $10.00 \pm 0.52 \mathrm{a}$ & $24.60 \pm 0.74 \mathrm{~b}$ \\
& $T$ value & $6.230^{* *}$ & $2.445^{*}$ & $0.221^{\mathrm{NS}}$ & $7.477^{* *}$ \\
$25^{\circ} \mathrm{C}$ & Sharqia & $11.90 \pm 0.28 \mathrm{a}$ & $66.67 \pm 0.76 \mathrm{a}$ & $7.02 \pm 0.14 \mathrm{a}$ & $20.00 \pm 0.53 \mathrm{a}$ \\
& Qena & $8.20 \pm 0.29 \mathrm{~b}$ & $48.60 \pm 0.66 \mathrm{~b}$ & $5.00 \pm 0.46 \mathrm{~b}$ & $14.33 \pm 0.21 \mathrm{~b}$ \\
& $T$ value & $9.081^{* *}$ & $18.006^{* *}$ & $4.185^{* *}$ & $9.865^{* *}$ \\
$35^{\circ} \mathrm{C}$ & Sharqia & $8.00 \pm 0.36 \mathrm{a}$ & $52.60 \pm 0.46 \mathrm{a}$ & $5.20 \pm 0.26 \mathrm{a}$ & $14.08 \pm 0.22 \mathrm{a}$ \\
& Qena & $5.60 \pm 0.07 \mathrm{~b}$ & $32.19 \pm 0.42 \mathrm{~b}$ & $3.30 \pm 0.12 \mathrm{~b}$ & $10.99 \pm 0.20 \mathrm{~b}$ \\
& $T$ value & $6.532^{* *}$ & $33.029^{* *}$ & $6.635^{* *}$ & $10.388^{* *}$ \\
$45^{\circ} \mathrm{C}$ & Sharqia & $3.30 \pm 0.10 \mathrm{a}$ & $16.70 \pm 0.24 \mathrm{a}$ & $2.20 \pm 0.05 \mathrm{a}$ & $5.56 \pm 0.12 \mathrm{a}$ \\
& Qena & $2.90 \pm 0.13 \mathrm{~b}$ & $14.20 \pm 0.38 \mathrm{~b}$ & $1.90 \pm 0.03 \mathrm{~b}$ & $5.26 \pm 0.10 \mathrm{a}$ \\
& $T$ value & $2.440^{*}$ & $5.563^{* *}$ & $5.468^{* *}$ & $1.925^{\mathrm{NS}}$ \\
\hline
\end{tabular}

In a vertical column, means with the same letter(s) are not significantly different $(P>5 \%)$. **Denotes highly significant, ${ }^{*}$ denotes significant, NS denotes insignificant, $(\mathrm{df}=8)$

were $\left(12.4^{\circ} \mathrm{C}\right)$ for the Sharqia strain which was higher than the Qena strain $\left(9.72^{\circ} \mathrm{C}\right)$ (Fig. 1).

\section{Life table parameters}

Table 3 illustrated the effect of the intrinsic rate, the rate of net reproduction, and the finite rate for Sharqia treated strain with the increase of the temperature from 15 to $45^{\circ} \mathrm{C}$, while both average generation time and doubling time showed a contrary trend with respect to that of Qena. Moreover, the mean generation time for the Sharqia strain showed higher values than that for the Qena.

On the other hand, the life table parameters for $O$. nubilalis of both localities clarify that the mean generation time $T_{c}$ was shorter when female reared on $45^{\circ} \mathrm{C}$.

\section{Discussion}

Thermal fluctuation may vary between species, populations, development stages, other ecological factors, and treated or untreated food source (Bueno et al., 2009). Temperature is the most vital factor affecting the rate of development of insects (Haile et al., 2002). The knowledge of thermal constants and lower development thresholds provides creative prediction model to determine the developmental rate of a particular species of arthropod and timing pests' control in different environments (Quesada-Moraga and Santiago-A'lvarez, 2000).

Our results were in accordance with that reported by Hassan et al. (2008) who mentioned that the long geographical distance between Qalubiya and Qena and the difference in climatic conditions as well indicating that there was high genetic differentiation between two Sesamia cretica strains. The developmental rates of the undeveloped stages of $O$. nubilalis between the two treated strains varied due to the difference of prevailed temperature in the two localities. These findings are in accordance with that of Rahman and Khalequzzaman (2004) on stem borers and contradict with that obtained

Table 3 Life table parameters for Ostrinia nubilalis under different constant temperature

\begin{tabular}{|c|c|c|c|c|c|}
\hline Temp. & Intrinsic rate $\left(r_{m}\right)$ & $\begin{array}{l}\text { Net reproductive rate } \\
\left(R_{0}\right) \text { Female/female/egg }\end{array}$ & Generation time (day) & $\begin{array}{l}\text { Finite rate of increase } \\
\text { Female/female/egg }\end{array}$ & Doubling time (day) \\
\hline \multicolumn{6}{|l|}{ Sharqia } \\
\hline $15^{\circ} \mathrm{C}$ & $0.02 \pm 0.003$ & $55.11 \pm 1.218$ & $180.10 \pm 1.893$ & $0.99 \pm 0.066$ & $43.01 \pm 0.881$ \\
\hline $25^{\circ} \mathrm{C}$ & $0.10 \pm 0.017$ & $49.95 \pm 1.020$ & $166.90 \pm 1.613$ & $1.10 \pm 0.083$ & $40.00 \pm 0.832$ \\
\hline $35^{\circ} \mathrm{C}$ & $0.09 \pm 0.015$ & $109.99 \pm 2.456$ & $70.54 \pm 0.903$ & $1.12 \pm 0.044$ & $19.92 \pm 0.350$ \\
\hline $45^{\circ} \mathrm{C}$ & $0.14 \pm 0.007$ & $259.77 \pm 2.193$ & $59.61 \pm 0.645$ & $1.22 \pm 0.124$ & $8.66 \pm 0.194$ \\
\hline \multicolumn{6}{|l|}{ Qena } \\
\hline $15^{\circ} \mathrm{C}$ & $0.154 \pm 0.008$ & $170.03 \pm 1.109$ & $70.10 \pm 0.692$ & $1.00 \pm 0.0318$ & $9.20 \pm 0.411$ \\
\hline $25^{\circ} \mathrm{C}$ & $0.123 \pm 0.006$ & $165.44 \pm 1.222$ & $69.90 \pm 0.738$ & $1.016 \pm 0.105$ & $9.90 \pm 0.236$ \\
\hline $35^{\circ} \mathrm{C}$ & $0.100 \pm 0.016$ & $120.43 \pm 1.024$ & $66.66 \pm 0.925$ & $1.029 \pm 0.026$ & $11.40 \pm 0.232$ \\
\hline v $45^{\circ} \mathrm{C}$ & $0.910 \pm 0.052$ & $100.22 \pm 1.156$ & $54.40 \pm 1.294$ & $1.066 \pm 0.032$ & $13.20 \pm 0.314$ \\
\hline
\end{tabular}


by Calvin et al. (1991) on Ostrinia nubilais. Our results revealed highly significant differences within each treated stage of the same geographical strain and different tested temperature. This probably may be due to the differences in temperature fluctuation; and these results are similar to that of Haile et al. (2002). It was noticed that the decrease in the developmental period with increasing temperatures causes an increase in the developmental rate as mentioned by Haddad et al. (1999). An opposite trend was reported in case of other pyralid as rice stem borers (Rahman and Khalequzzaman, 2004). In our result, Qena treated strain showed a higher value for zero of development than the Sharqia strain; these findings agreed with that of Orang et al. (2014).

The biology of insects requires the determination of their life table parameters as the net reproductive rate being higher in the Qena strain at 15,25 , and $35^{\circ} \mathrm{C}$ than in Sharqia leading to decrease in doubling time and slightly rising both the finite rate and intrinsic rate for $O$. nubilalis. The previous data matched with that reported by Sedighi et al. (2016) on S. cretica.

The mean generation period and doubling time may be decrease by increasing the temperature as mentioned by some authors (Ebed, 2008; Firake and Khan 2014).

\section{Conclusion}

It could be concluded that the duration and thermal requirements of two populations of the silica nanoparticle-treated strain of Ostrinia nubilalis (Hüb.) from different localities and its development at four constant temperatures $\left(15,25,35\right.$, and $\left.45^{\circ} \mathrm{C}\right)$ were significantly different between each other. The developmental time increased significantly with the increasing temperature within the range of both strains. Such information and life table are crucial to predict the seasonal abundance of the adult $O$. nubilalis in the field, which is essential for the successful implantation of control measures and enables us to determine the best time for controlling with better performance.

\section{Acknowledgements}

The author is very grateful to all colleges, Pests and Plant Protection Department, National Research Centre, for their valuable help provided.

\section{Significant statement}

This study is important for the clean environment free of the pollution of chemical insecticides, create new agents from local available materials safe, easy preparing, cheap, possible use in combination with other biological control method of IPM program, decrease build up resistance strains of the insect.

\section{Funding}

The research was financed by author.

\section{Availability of data and materials}

The datasets used and/or analyzed during the current study are available from the corresponding author on reasonable request.
Authors' contribution

The author read and approved the final manuscript.

Ethics approval and consent to participate

Not applicable.

Consent for publication

Not applicable.

\section{Competing interests}

The author declares that he has no competing interests.

\section{Publisher's Note}

Springer Nature remains neutral with regard to jurisdictional claims in published maps and institutional affiliations.

Received: 20 September 2018 Accepted: 4 January 2019

Published online: 21 January 2019

\section{References}

Bueno RCOF, Parra JRP, Bueno AF (2009) Biological characteristics and thermal requirements of a Brazilian strain of the parasitoid Trichogramma pretiosum reared on eggs of Pseudoplusia includens and Anticarsia gemmatalis. Biol Control 51:355-361

Calvin DD, Higgins RA, Knapp MC, Poston FL, Welch SM, Schowers WB, Witkowski JF, Mason CE, Chiang HC, Keaster AJ (1991) Similarities in developmental rates of geographically separate European corn borer (Lepidopter: pyrralidae) population. Environ Entomol 20(2):441-449

Campbell A, Frazer BD, Gilbert N, Gutierrez AP, Mackauer M (1974) Temperature requirements of some aphids and their parasites. J Appl Ecol 11:431-438

Chi H, Su HY (2006) Age-stage, two-sex life tables of Aphidius gifuensis (Ashmead) (Hymenoptera: Braconidae) and its host Myzus persicae (Sulzer) (Homoptera: Aphididae) with mathematical proof of the relationship between female fecundity and the net reproductive rate. Environ Entomol 35:10-12

Chinnamuthu CR, Boopathi PM (2009) Nanotechnology and agroecosystem. Madras Agric J 96(1-6):17-31

Ebed AR (2008) Ecological, physiological and genetical variation in strains of some corn borers under the prevailing environmental condition in Egypt. Ph. D. Thesis, Faculty of Science Ain Shams University, 116Pp.

Ebeid AR (2012) Impact of different constant temperature on some growth parameters of Tropinota squalida Scop. under laboratory and field conditions. J Appl Sci Res 8(7):3539-3543

Ebeid AR, Abdel Rahman AA, Gesraha MA (2013) Impact of diatomaceous earth (silica nano-particles) on Alfalfa Grasshopper, Heteracris littoralis (Rambur) (Orthoptera: Acrididae) under laboratory conditions. Egypt J Biol Pest Control 23(2):325-330

Ebeid AR, Sammour EA, Zohdy NZ (2015) Role of challenger pesticide and plant extracts on some physiological parameters of the cotton leafworm, Spodoptera littoralis (Boisd.). Arch Phytopathol Plant Protect 48(5):385-392

Ebeid AR, Gesraha MA, Abdou WL (2017) Effects of Cyfluthrin insecticide on Agrotis ipsilon immature stages development with respect to different temperature. ARRB 15(6):1-9

Firake DM, Khan MA (2014) Alternating temperatures affect the performance of Trichogramma species. J Insect Sci 14:41

Haddad ML, Parra JRP, Moraes RCB (1999) Me'todos para estimaros limites te'rmicos inferior e superior de desenvolvimento de insetos. FEALQ, 29p. Piracicaba, São Paulo, Brazil. [Number of larval instars of Tuta absoluta (Meyrick) in tomato genotypes]

Haile AT, Hassan SA, Ogol CKPO, Baumgartner J, Sithanantham S, Monje JC, Zebits CPW (2002) Temperature-dependent development of four egg parasitoids Trichogramma species (Hymenoptera; Trichogrammatidae). Biocontrol Sci Tech 12:555-567

Hassan AA, Oraby HAS, Amr EA, Ali Fl, Ebeid ARR (2008) Genetic variation within and between three strains of Sesamia cretica Led. (Lepidoptera: Noctuidae) in Egypt using RAPD analysis. J Genet Eng Biotechnol (NRC) 4(1):107-116

Orang FS, Aghdam HR, Abbasipour H, Askarianzadeh A (2014) Effect of temperature on developmental rate of Sesamia cretica (Lepidoptera: Noctuidae) immature stages. J Insect Sci 14(197):1-7 
Quesada-Moraga E, Santiago-A'lvarez C (2000) Temperature related effects on embryonic development of the Mediterranean locust, Dociostaurus maroccanus. Physiol Entomol 25:191-195

Rahman MT, Khalequzzaman M (2004) Temperature requirements for the development and survival of rice stem borers in laboratory conditions. Entomologica Sinica 11:47-60

Roy M, Brodeur J, Cloutier C (2003) Effect of temperature on intrinsic rate of natural increase $(\mathrm{rm})$ of a coccinellid and its spider mite prey. Biol Control 48:57-72

Sedighi L, Ranjbar Aghdam H, Imani S, Shojai M (2016) Comparative demography of Sesamia cretica Lederer (Lepidoptera: Noctuidae) on its two the most important natural hosts, maize and sugarcane. J Agr Sci Tech Vol 18:1807-1818

Tuan SJ, Li NJ, Yeh CC, Tang LC, Chi H (2014) Effects of green manure cover crops on Spodoptera litura (Lepidoptera: Noctuidae) populations. J Econ Entomol 107(3):897-905

\section{Submit your manuscript to a SpringerOpen ${ }^{\circ}$ journal and benefit from:}

- Convenient online submission

Rigorous peer review

- Open access: articles freely available online

High visibility within the field

- Retaining the copyright to your article

Submit your next manuscript at $\boldsymbol{\nabla}$ springeropen.com 